\title{
New faunistic record of two species of genus Calvia (Coleoptera: Coccinellidae: Coccinellini) from India and Myanmar
}

\author{
Priyanka Das ${ }^{1}$, Goutam Kumar Saha ${ }^{2}$, Devanshu Gupta ${ }^{1}$, Kailash Chandra ${ }^{1}$ \\ 1 Zoological Survey of India, M Block, New Alipore, 700053 Kolkata, West Bengal, India \\ 2 Department of Zoology, University of Calcutta, 35 Ballygunge Circular Road, 700019 Kolkata, India \\ Corresponding author: Priyanka Das (priyankajan03@gmail.com)
}

Received 11 August 2020 | Accepted 19 November 2020 | Published 31 December 2020

Citation: Das P, Saha GK, Gupta D, Chandra K (2020) New faunistic record of two species of genus Calvia (Coleoptera: Coccinellidae: Coccinellini) from India and Myanmar. Travaux du Muséum National d'Histoire Naturelle "Grigore Antipa” 63(2): 195-201. https://doi.org/10.3897/travaux.63.e57502

\begin{abstract}
Calvia sichuanica Kovár (Coleoptera: Coccinellidae: Coccinellini) is reported for the first time from India and Myanmar, previously known only from China. Also, Calvia explanata Poorani, from Sikkim and Darjeeling, is newly reported from Manipur, state of India.
\end{abstract}

\section{Keywords}

Northeastern hill province, ladybird beetles, distributional range expansion.

The genus Calvia Mulsant, 1846 (Coleoptera: Coccinellidae: Coccinellini) is distributed in the Palaearctic and Oriental regions, comprises more than 20 species of them, 14 species are known from India (Iablokoff-Khnzorian 1982; Booth 1997; Kuznetsov 1997; Poorani 2002; Poorani 2014). Booth (1997) reviewed the genus and provided the habitus and illustrations of male and female genitalia of the Indian species except for C. quindecimguttata (Fabricius, 1777). The most recent species described from Himalayan Region is C. explanata Poorani, 2014. Additional significant illustrations of habitus, male and female genitalia are provided in Iablokoff-Khnzorian (1982), Ren et al. (2009), and Yu (2010). Kováŕ (2007: 71) in Catalogue of Palearctic Coleoptera proposed Calvia sichuanica as a replacement name for the C. sicardi Mader, 1930, as the original name, Agrabia sicardi 
Nunenmacher, 1912 was preoccupied. Ren et al. (2009) provided the habitus and male genitalia of C. sicardi Mader, 1930 and reported the species only from China, overlooking the replaced name, C. sichuanica Kovár, 2007. While working on a collection of Coccinellidae in National Zoological Collection of Zoological Survey of India, Kolkata (NZSI), the specimens of C. sichuanica Kovár, 2007 and a recently described species, C. explanata Poorani, 2014 were found. The purpose of the paper is to report C. sichuanica Kovár, 2007 for the first time from India and Myanmar along with the supported illustrations of male and female habitus. Calvia explanata Poorani, 2014, described from Sikkim and Darjeeling is also newly reported from Manipur state. Most of the species of the genus are restricted to the Himalayan region with only two species C. andrewesi (Weise, 1908), and C. sykesii (Crotch, 1874) extended their distribution towards penninsular India.

The materials for the present study are housed in the National Zoological Collection of Zoological Survey of India, Kolkata (NZSI). Male genitalia were dissected, cleaned in $10 \% \mathrm{KOH}$ solution, and fixed in glycerol gelatin slides prior to the study. The specimens were examined using a Nikon SMZ25 stereo microscope, and the photographs were taken using DS-Ri2 camera with NIS Elements BR 5.10.00 imaging software. Images were improved using Adobe Photoshop CS5. Morphological terminology used in the description of adults follows Ślipiński (2007), Ślipiński \& Tomaszewska (2010) and Lawrence et al. (2011).

The following abbreviations are used for various measurements of the body parts given in the descriptions of the species:

TL-total body length, from apical margin of clypeus to apex of elytra

PL-pronotal length, from the middle of anterior margin to margin of basal foramen

PW-pronotal width at widest part

EL-elytral length along suture, including scutellum

EW-elytral width across both elytra at widest part.

NZSI-National Zoological Collection of Zoological Survey of India, Kolkata

Taxonomic accounts

Genus Calvia Mulsant, 1846

Type species: Coccinella decemguttata Linnaeus, 1767.

\section{Calvia sichuanica Kováŕ, 2007}

(Figs 1A, 1B)

Calvia sicardi Mader, 1930: 163, figure 3, habitus; Ren et al., 2009: 184, 185, figures 244a habitus, 244b abdomen, 244c-e male genitalia, [homonym]. [Type locality: China, Sze-Chwan Province, Mts. Yunling].

Calvia sichuanica Kovář, 2007: 608 [nom. nov.]. 


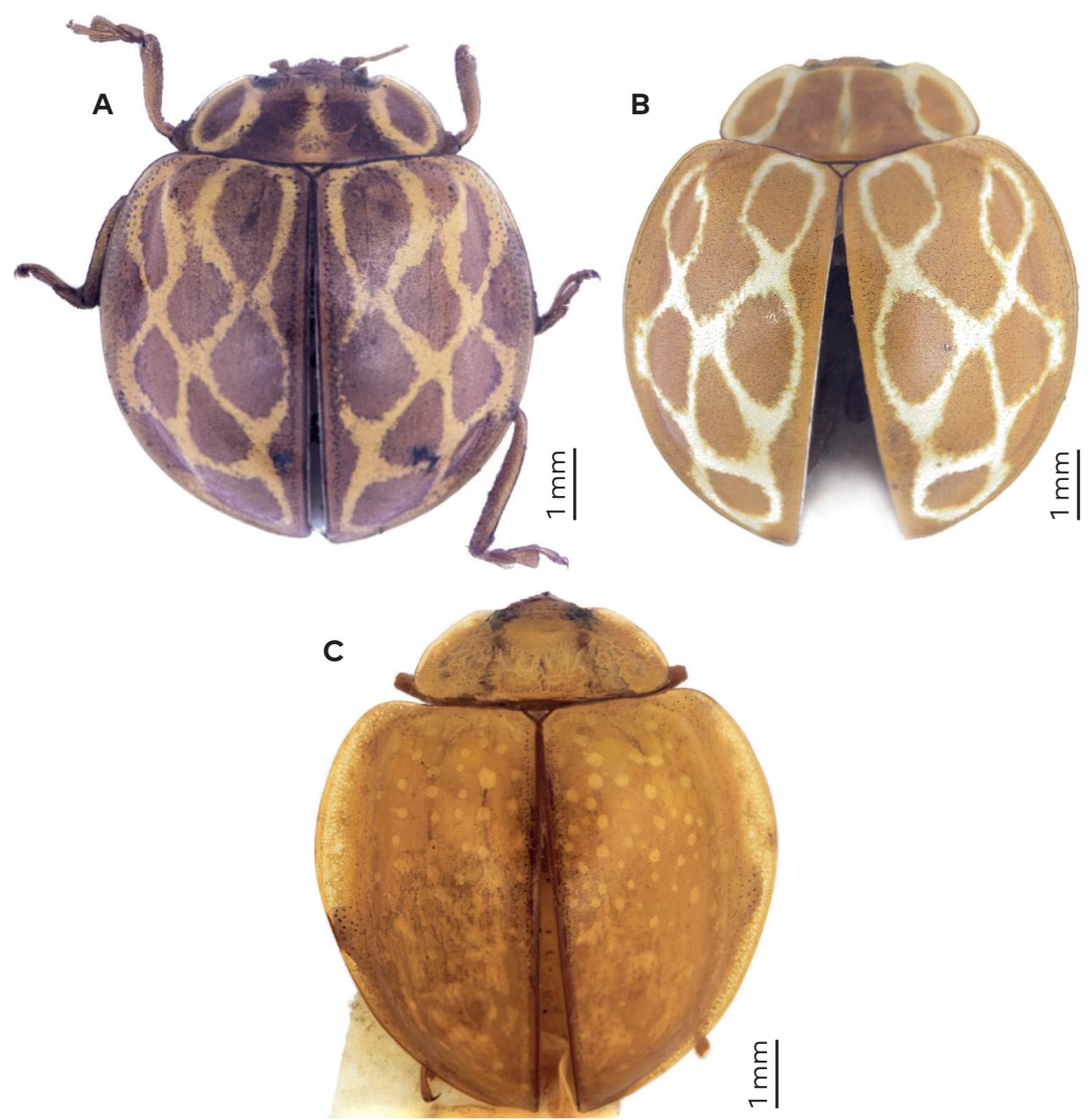

Figure 1. Calvia sichuanica Kováŕ, 2007: A - male habitus, dorsal; B - female habitus, dorsal; C - Calvia explanata Poorani, 2014, male habitus, dorsal.

Material examined. India: Manipur, Ukhrul, 27.xii.1992, 1 female, Registration No. 27935/H4A, leg. RS Mridha [NZSI]. North East Burma (Myanmar): Kambaiti, 7000 feet, 18.iv.1934, 1 male, Registration No. 27936/H4A, leg. R. Malaise [NZSI]. Measurements. TL: $6.80-7.20 \mathrm{~mm}$; TW: $6.20-6.70 \mathrm{~mm}$; TL/TW: 1.07-1.10; PL/ PW: 0.33-0.37; EL/EW: 1.76-1.78.

Body. Dorsum golden-yellowish except for transparent lateral margins of pronotum and elytra; ventral side brown. Dorsum oval, convex; just before mid-elytra broadest; elytra longer than wide; glabrous dorsally.

Head. Clypeal margin truncate between lateral projections; eyes prominent, inner ocular margins distinct anteriorly. 
Antennae. Elongate with 11 antennomeres; antennal club 3 antennomeres, asymmetrical; terminal antennomere oval, flattened apically.

Pronotum. Two oval maculae at lateral edge, one longitudinal at middle.

Scutellar shield. Triangular, broadest at pronotal base.

Elytra. Elytron with 5 golden-yellowish maculae (arranged as 2-2-1), lined with buttery yellow pattern (Figs 1A, 1B) 2 oblique near scutellar shield, 2 near midelytron, and 1 near apex; surface with coarse punctures.

Thorax. Brown, ventral side covered with pubescence. Intercoxal prosternal process convex, without carinae. Mesoventrite medially semi-circularly marginated. Metaventrite with discrimen. Epipleuron wide, deeply concave for accommodation of legs, complete at apex.

Legs. Pro-femur with depression or foveae for holding pro-tibiae when retracted. Meso-and metatibiae with double apical spurs. Tarsal claws appendiculate.

Abdomen. Abdomen with six ventrites, in both sexes. Abdominal postcoxal lines incomplete, short, ends before posterior margin of ventrite 1. Posterior margin of ventrite 5 straight, superficially and widely marginated, that of ventrite 6 emarginate in male and arcuate in female. marginated

Distribution. (Fig. 2). India: Manipur (this paper). Elsewhere: China (Ren et al. 2009) and Myanmar (this paper).

Remarks. This species is recorded for the first time from India (Manipur) and Myanmar, previously known from China. In external appearance, C. sichuanica

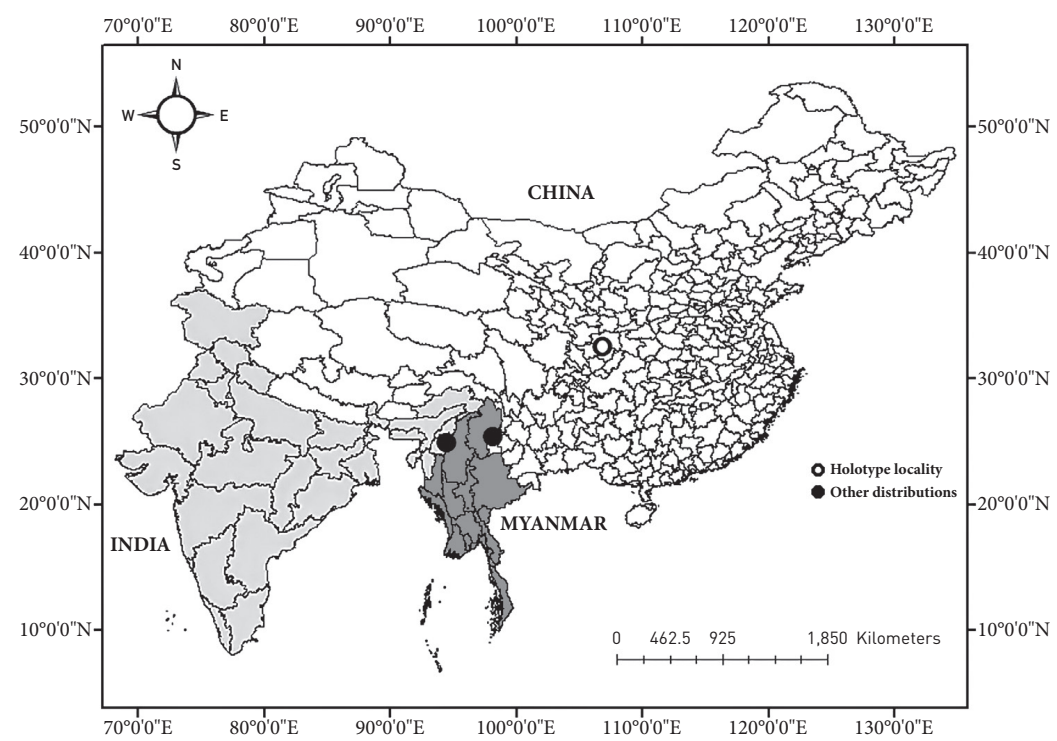

Figure 2. Map of India, Myanmar and China, showing distributional records of C. sichuanica Kovár, 2007. 
closely resembles C. vulnerata (Hope, 1831), but the structure of male and female genitalia resembles with that of C. championorum Booth, 1997. In C. vulnerata, elytron usually has 6 either yellow or black spots and with or without a pale outer ring. In contrast, in C. sichuanica, elytron has 5 golden yellow, with a pale yellow outer ring. In $C$. championorum, the parameres are equal in length of penis guide, penis swollen at apical one-third portion, and spermatheca much slender and broader near the base, whereas in, C. sichuanica, the parameres are slightly longer than penis guide, penis narrow and twisted to a thread-like structure and spermatheca entirely slender and comparatively less curved.

Calvia explanata Poorani, 2014

(Figs 1C; 3)

Calvia explanata Poorani, 2014: 2, figures 1a-c, 2a-f.

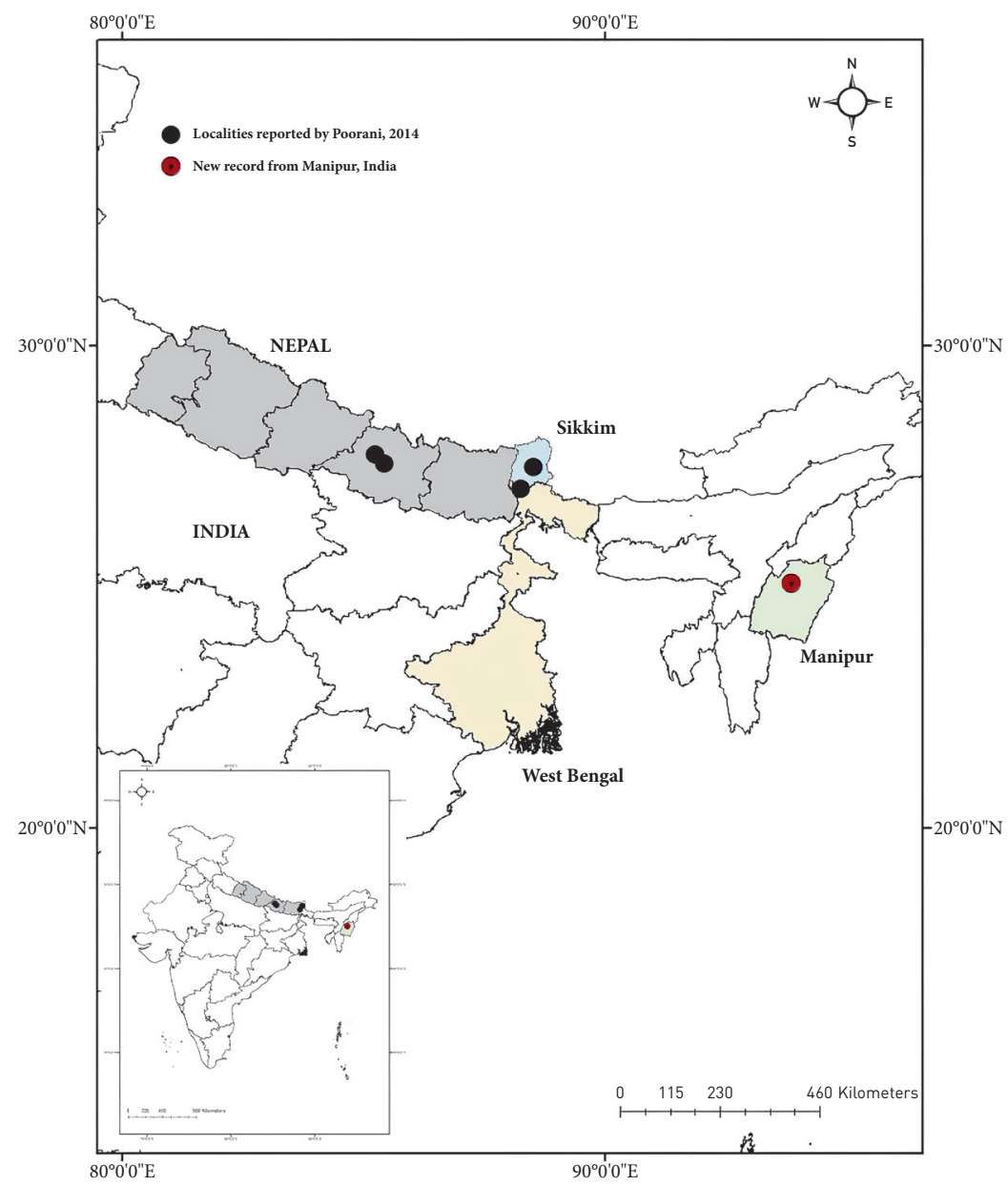

Figure 3. Map of India and Nepal, showing distributional records of C. explanata Poorani, 2014. 
Material examined. India: Manipur: Koubru Peak, 06.xii.2017, 25.0856 N, 93.8872 E, 2 exs., Registration No. 27934/H4A, leg. C. Tuboi [NZSI].

Distribution. India: Sikkim (Pantok, Mangam), Manipur (Koubru Peak, this paper) and West Bengal (Darjeeling); Nepal (Poorani 2014).

Remarks. Poorani (2014) described this species from the Himalayas; Manipur (Koubru Peak) is a new distributional record for the species (Fig. 3).

Both the species of Calvia Mulsant, 1846; C. sichuanica Kovár., 2007 and C. explanata Poorani, 2014 were recorded from Palearctic regions. This new distributional addition confirms that these species are not restricted to that region and has extended their range to Indo-Malayan region as well (Figs 2, 3).

\section{Acknowledgements}

The authors are thankful to Dr Karol Szawaryn (Museum and Institute of Zoology, Polish Academy of Sciences, Warszawa, Poland) for his support in the literature and crucial suggestions. We also wish to thank Dr Xingmin Wang (South China Agricultural University, Guangzhou, China) for his help in providing literature. We are grateful to three anonymous reviewers for their valuable suggestion for improving the manuscript. The paper is a part of PhD work by the first author.

\section{References}

Booth RG (1997) A review of the species of Calvia (Coleoptera: Coccinellidae) from the Indian Subcontinent, with descriptions of two new species. Journal of Natural History 31: 917-934. DOI: 10.1080/00222939700770451

Iablokoff-Khnzorian SM (1982) Les Coccinelles Coléoptères-Coccinellidae Tribu Coccinellini des regions Palearctique et Orientale [The Coleopteran Ladybirds Coccinellidae, Tribe Coccinellini of Palearctic and Orient]. Boubée, Paris, 568 pp. [in French]

Kovář I (2007) Family Coccinellidae Latreille, 1807. In: Löbl I, Smetana A (Eds) Catalogue of Palaearctic Coleoptera, Vol 4. Apollo Books, Stenstrup, 568-631.

Kuznetsov VN (1997) Lady Beetles of the Russian Far East. Memoir No. 1. Center for Systematic Entomology by the Sandhill Crane Press, Gainesville, Florida, United States, 248 pp.

Lawrence JF, Ślipiński SA, Seago AE, Thayer MK, Newton AF, Marvaldi AE (2011) Phylogeny of the Coleoptera based on morphological characters of adults and larvae. Annales Zoologici 61: 1-217. http://dx.doi.org/10.3161/000345411x576725 
Mader L (1930) Neue Coccinelliden aus Yün-nan und Szetschwan (China) [New Coccinellids from Yün-nan and Szetschwan (China)]. Entomologischer Anzeiger 10: 161-166. [in German]

Mulsant E (1846) Histoire naturelle des coléoptères de France [Natural history of beetles in France]. Sucicollis.-Securipalpes. Maison, Paris, 280 pp. [in French]

Poorani J (2002) An annotated checklist of the Coccinellidae (Coleoptera) (excluding Epilachninae) of the Indian subregion. Oriental Insects 36(1): 307-383.

Poorani J (2014) Calvia explanata sp. n. (Coleoptera: Coccinellidae: Coccinellinae) from the Indian Subcontinent. Biodiversity Data Journal. 2, e1164. DOI:10.3897/BDJ.2.e1164

Ren S, Wang X, Pang H, Peng Z, Zeng P (2009) Colored pictorial handbook of ladybird beetles in China. Science Press, Beijing, 336 pp. [in Chinese]

Ślipiński SA (2007) Australian ladybird beetles (Coleoptera: Coccinellidae) their biology and classification. ABRS, Canberra and CSIRO Publishing, Melbourne, $762 \mathrm{pp}$.

Ślipiński SA, Tomaszewska W (2010) Coccinellidae Latreille, 1802. In: Leschen RAB, Beutel RG,LawrenceJF(Eds) Handbook ofZoology. Vol.2. Coleoptera. Walter de Gruyter GmbH \& Co. KG., Berlin/New York, pp. 454-472. https://doi.org/10.1515/9783110911213.454

Yu G (2010) Chinese lady beetles (The subfamily Coccinellinae). China Press, Beijing, 180 pp. [in Chinese with English summary] 